\title{
Notas sobre Borges y la crítica reciente
}

\author{
"Vida y muerte le han faltado a mi \\ vida. De esa indigencia, mi laborioso \\ amor por estas minucias".
}

JORGE LUIS BORGES

Durante más de treinta años de continua actividad literaria el notable escritor Jorge Luis Borges se ha dedicado con ejemplar fidelidad a su vocación, revelando su singular personalidad primero en la poesía, dentro de la estética ultraísta, casi simultáneamente en el ensayo crítico y más tarde en la narración. Hace algunos años no existía sino para los escritores aristocráticos, para los paladares más exigentes. ${ }^{1}$ Aunque Borges inicia su obra de narrador en 1935 , de la publicación de $E l$ Aleph (1949), primer libro de ficciones lanzado al gran público, data su consagración definitiva. Referirse a un solo género equivale a falsear la unidad esencial en la obra de Borges. Sin embargo, es en el cuento sobre todo donde estamos frente al Borges cabal y completo, que goza de merecido renombre universal. $\mathrm{Y}$ decir que es autor de una obra original y sin precedentes, ${ }^{2} \mathrm{y}$ que es una de las figuras más destacadas que escribe actual-

1 Esto no quiere decir, como ya veremos, que no fuera conocido Borges desde un primer momento. Por ejemplo, Ramón Gómez de la Serna [Revista de Occidente, IV (Núm. 10, abril de 1924), pp. 123-127] reseñó Fervor de Buenós Aires y en la misma revista [IX (Núm. 25, julio de 1925), pp. 125-127] Benjamín Jarnés dedica una nota a Inquisiciones.

2 Sobre la originalidad de Borges dijo Pedro Henríquez Ureña: "Habrá quieness piensen que Borges es original porque se propone serlo. Creo al revés: que 
mente en lengua española no exagera su sitio de honor en las letras contemporáneas.

Sin querer negar sus positivos méritos de poeta y ensayista, son los cuentos de Borges, casi siempre de raíz filosófica, que deslumbran por su asombrosa erudición e imaginación sin límites. Esta prosa está sometida a la razón y al análisis más riguroso. $\mathrm{Y}$, aun dentro del género fantástico, su prosa discute, refuta, conversa, especula y funciona según premisas y postulados bien definidos. Borges, pues, hace una literatura inteligente para minorías selectas. Evita la incoherencia y la divagación me. diante el esfuerzo sostenido y la disciplina más severa. Al estructurar sus relatos, no hay nada accidental en su ejecución. Cadá Elemento, por mínimo y neutro que aparezca a primera vista, corresponde a un plan previo, cuidadosamente elaborado y premeditado. Borges no nos defrauda si somos capaces de seguir las pistas sutiles de la narración. En la mayoría de los casos. sin embargo, este constante juego de advertencias tan sólo se nos revela plenamente al llegar a las últimas frases del cuento. Sin duda el lector advierte en seguida una marcada voluntad de desconcierto en la técnica narrativa de Borges. Pero la intencionada ambiguiedad y los repetidos equívocos no sirven únicamente para precipitar sorpresas sino que también responden a un deseo de presentar nuevas y desconocidas fases de la compleja realidad. ${ }^{3}$ En el fondo, como ha señalado el perspicaz crítico Emir Rodríguez Monegal, Borges está convencido de la irrealidad del mundo de las apariencias. ${ }^{4}$ Siempre vigilante de

Borges será original hasta cuando se proponga no serlo...", "Desagravio a Borges", Sur, XII (Núm. 94, julio de 1942), p. 14.

3 En uno de los mejores trabajos que tenemos sobre Borges, Enrique Pezzoni ["Aproximación al último libro de Borges", Sur (Núm. 217-218, nov. y dic. 1952), pp. 101-123] ha apuntado el asombro de Borges ante el mundo como la primera condición del vivir consciente. Condena la existencia reducida a la rutina y la costumbre (pp. 109-110).

4 Emir Rodríguez Monegal, "Borges: Teoría y práctica", Número, VI (Núm. 27, diciembre de 1955), p. 136. De la misma página nos permitimos transcribir lo siguiente: ". . fuera del presente el Tiempo no existe y que este mismo presente contemplado por nuestro yo es de naturaleza ilusoria. En la base de sus especulaciones metafísicas hay la intuición de la vanidad del conocimiento intelectual y la convicción de que es imposible penetrar el diseño último del mundo (si lo hay)" (p. 136). 
todas las posibilidades literarias y expresivas, ha creado una cbra casi demasiado perfecta para los iniciados que sepan gozar de sus finezas intelectuales y estilísticas. Cada palabra lleva en sí su función explicativa. Por su temática y su ejecución las ficciones de Borges son difíciles y dos constantes las rigen: por una parte, una vasta e inverosímil erudición y una deslumbrante imaginación por otra. Ambas están enderezadas a la indagación metafísica y a un afán de conocimiento esencial. Y, por último, su fabulosa capacidad de invención parece ser inagotable.

Por la naturaleza y la calidad de su obra, Borges, desde luego, ha sido un tema candente en la crítica. Hay pocos autores más discutidos que él. Basta decir que es una figura polémica; despierta pasiones; y nadie puede quedarse pasivo e indiferente ante su literatura. Opositores y admiradores. Los hay que le re. prochan un supuesto despego a lo nacional, otros ven su argentinidad esencial; ${ }^{5}$ un sector de la crítica condena en él la mistificación intencionada y malévola de su arte ajedrecístico, otro encomia fervorosamente estas excelencias rebuscadas que no son para todos. ${ }^{6}$ Borgismo y antiborgismo, pues.

Los artículos y reseñas que afortunadamente tenemos so. bre Borges forman ya un necesario y macizo cuerpo de materiales. Aunque no es nuestra intención estudiar aquí "el caso Borges" y su evolución en la crítica, quisiéramos recordar unos hitos fundamentales. En 1933, cuando había publicado ya tres libros de verso y cinco de prosa, la revista bonaerense Megáfono ["Discusión sobre Jorge Luis Borges", Megáfono, III (Núm. 11, agosto de 1933), pp. 13-33] celebró una encuesta sobre el escritor. En ella tomaron parte quince escritores que hablaban por turno con el privilegio de comentar los textos anteriores. Una lectura de estos breves estudios dedicados a la obra de Borges confirma una vez más el rasgo distintivo de

5 Ningún tema más comentado. Un texto indispensable de Borges para conocer su actitud es "El escritor argentino y la tradición", Sur (Núm. 232, enero-febrero 1955), pp. 1-8. Leyó esta conferencia en el Colegio Libre de Estudios Superiores en 1951 y ha sido publicada ya en varios lugares.

6 Con tono irónico y frívolo Néstor Ibarra recoge las opiniones despreciativas en su nota "Jorge Luis Borges", Lettres Fraņ̧aises (Núm. 14, 1 de octubre 1944). pp. 9-12. Por lo demás, estas páginas de Ibarra sirven de prólogo a la traducción francesa de Ficciones (Paris: Gallimard, 1952). 
casi toda la crítica sobre él. La dicotomía es bien clara: admiración o negación. $Y$, por lo demás, pasiones en el ataque o la defensa. Sin reseñar el contenido múltiple de todos esos trabajos, quizá interese destacar algunas opiniones -muy diferentes entre si -puesto que en general son las que han persistido aún en la crítica de 1955. Petit de Murat, quien admira a Borges casi sin reservas, y Anzoátegui, quien lo niega rotundamente, representan los antípodas de la encuesta. Eduardo Mallea por su parte, cree que Borges es fundamentalmente poeta y subraya su valor de estilista. Tomás de Lara llega a decir que tan sólo es poeta - y nada más - pero advierte al mismo tiempo su estancamiento retórico. Ghida reconoce el mérito del poeta, pero lamenta las minucias en el prosista y rechaza su crítica por superficial y fragmentaria. León Ostrov opina que sus actividades de poeta y crítico se estorban, notando primero en el verso una ausencia de contenido humano y luego en la crítica aguda, fina y erudita, una falta de aliento para crear obra de mayor alcance. (También Vignale ataca el fragmentarismo de Borges.) Anderson Imbert, aunque considera a Borges inteligente, estudioso, con voluntad de estilo y superior a sus compañeros de generación, arremete violentamente contra el ensayista y el crítico. (De paso, Radaelli satirizó la nota de Anderson Imbert. quien tenía a la sazón veintitrés años, y así, al margen de la discusión, surgió una polémica entre los dos). Otra crítica: para Lisardo Zía, el pecado mayor de Borges es el borgismo de sus epígonos. Por otro lado, Amado Alonso elogia la "responsabilidad, sinceridad y afán de exactitud" (p. 19) que caracterizan su obra, y Olazábal, al refutar a Anzoátegui, insiste en su escrupulosidad de escritor. Si bien Guglielmini no admite la metafísica ni la crítica de Borges, señala como virtudes su lucidez, autocrítica e infalibilidad dentro de un orbe reducido de la realidad y acaba por llamarlo "cabal hombre de letras" (p. 22). Drieu de la Rochelle había iniciado la encuesta ("Borges vaut le voyage", p. 14) y Rubens la termina en nombre de la dirección declarando el motivo de la discusión: "lo que Borges, entre nosotros, vale como ejemplo de precisión idiomática —que él fue el primero en practicar por estas tierras-. de devoción a la palabra frente a la chabacanería expresiva del 
ambiente, de lucha cotidiana contra el vocablo o el giro rebeldes" (p. 33).

Pasan algunos años. El Borges poeta se ha callado; ha refutado progresivamente al ultraísmo, pero ha empezado a dar a la estampa, a partir de 1935, sus ficciones singulares. En 1942 la revista Sur publica su conocido "Desagravio a Borges" [Sur, XII (Núm. 94, julio de 1942), pp. 7-34] para protestar por la exclusión de Borges en el fallo de la Comisión Nacional de Cultura. En ese homenaje colaboraron veintiún escritores de los más prestigiosos y, por ser documento de más fácil consulta que la encuesta de 1933, nos limitamos a destacar el valor crítico de las notas de Mallea, Luis Emilio Soto, Amado Alonso y Anderson Imbert. Aunque aparecen de vez en cuando unos pocos reproches a Borges y a su obra, nadie niega, no obstante ciertas desafecciones personales, su gran talento de literato excepcional.

Ultimamente (1954-1955) la bibliografía crítica sobre tan importante escritor ha sido notablemente enriquecida con tres libros?, cuyo comentario es el tema central de esta nota. Apresuradamente, antes de abordar su análisis, los clasificaríamos así: un estudio ponderado e interpretativo de una vertiente de su obra (Tamayo y Ruiz-Díaz); una aproximación ferrorosa a los textos borgeanos en su totalidad (Ríos Patrón); $y$, por último, una critica severa e incisiva del escritor, hecha desde la perspectiva de una generación más joven (Adolfo Prieto). En suma, a pesar de su marcada diferencia de tono y de método crítico, los tres libros parecen corresponder al noble propósito de una máxima comprensión de la obra estudiada y vienen oportunamente a constituir otro paso en la evoiución de la crítica sobre Borges. ${ }^{8}$

7 Adolfo Prieto, Borges y la nüeva generación, Letras Universitarias (Buenos Aires, 1954), pág. 90.

José Luis Ríos Patrón, Jorge Luis Borges, Editorial "La Mandrágora" (Buenos Aires, 1955), pág. 179.

Marcial Tamayo y Adolfo Ruiz-Díaz, Borges, enigma y clave, Editorial Nuestro Tiempo (Buenos Aires, 1955), pág. 170.

8 A última hora hemos leído el excelente y muy útil trabajo de Emir Rodríguez Monegal, "El juicio de los parricidas: Borges entre Escila y Caribdis", Marcba (Montevideo), Núm. 799, 27 de enero de 1956, pp. 20-23. El crítico ha arrancado 
Empecemos con la aportaciớn de Marcial Tamayo y RuizDíaz (Borges, enigma y clave). Ante todo su trabajo es serio y disciplinado, ecuánime y meditado en sus juicios. Los autores se han acercado a Borges más con rigor analítico que con una admiración desmesurada. Una actitud crítica digna de elogio. Creemos que su esfuerzo primordialmente interpretativo ha sido colmado de éxito. (Un innegable acierto: la riqueza de interpretaciones de cuentos enteros. ${ }^{9}$ ) La obra no aspira a ser total ni a estudiar los tres géneros cultivados por Borges. Como visión de conjunto han preferido enfocar los relatos, lc cual no impide frecuentes alusiones a la poesía y el ensayo pa. ra iluminar la prosa imaginativa. Aun así es el estudio más completo y ambicioso que tenemos sobre el escritor. Además. según dijimos, este método nos parece lícito: lo más típico en Borges es el cuento donde aparecen todos sus temas predilectos. Otro mérito de tan útil estudio es el de procurar ser siempre fiel a la intención de Borges mismo, citando sus propias reflexiones subre el arte y el estilo. Y Borges es - perdónese la perogrullada - sumamente consciente de la tarea literaria que se ha propuesto. Resumamos, pues, la estructura y el contenido de tan interesante trabajo de crítica literaria.

El libro que nos ocupa se divide en ocho capítulos y una breve introducción. Cada sección está dedicada a comentar un tema incesante (y Borges es un escritor de pocos temas funda. mentales, pero lo más fecundo es su insólito modo de encararlos desde infinitas perspectivas insospechadas) o un procedimientn estilístico, como revelan sus títulos respectivos : "Erudición y estilo" (I), "Misterio y exactitud" (II), "Rostros de la ambigüedad" (III), "Sentido de la biografía" (IV), "Teoría del destino" (V), "El tiempo y la memoria" (VI), "Palabra y realidad" (VII)

de un trabajo de H. A. Murena ("Martínez Estrada: la lección a los desposeidos", Sur, Núm. 204, octubre de 1951, pp. 1-18) para resumir la actitud de los jóvenes frente a la obra de Borges y también traza su evolución en la crítica. Lo había hecho antes con respecto a Martinez Estrada y Mallea aparentemente en el mismo periódico de Montevideo.

9 Hemos notado los generosos análisis de los siguientes cuentos: "La muerte y la brújula" (pp. 29-47), "El muerto" (pp. 52-56), "Historia del guerrero y la cautiva" (pp. 75-80), "El milagro secreto" (pp. 98-103); "Las ruinas circulares" (pp. 137-143); etcétera. 
y "El escritor" (VIII) . El último capítulo lo han fragmentado en pequeños apartados sintéticos (medida, obra y vida, actualidad, afectaciones, experiencia, eficacia expresiva, metáfora, la patria) que constituyen un resumen de su estética. Convendrís hacer notar también que esta bien pensada organización de sus materiales facilita una visión orgánica de Borges, y, por lo demás, el tema de cada capitulo se relaciona íntimamente con la materia del siguiente. En su conjunto, pues, un ensayo inteligente y a la altura de la nada fácil tárea que se han propuesto los dos auto. res.

Quizá el rasgo más distintivo de la prosa borgeana es la abrumadora acumulación de citas eruditas y referencias biblio. gráficas, ambas de la más extravagante procedencia y casi siempre desconocidas para el lector mediano. ${ }^{10}$ Tener una cultura literaria y filosófica es una indispensable contraseña para franquear la puerta de este mundo denso y enrarecido. Como señalan acertadamente Tamayo y Ruiz-Díaz (I), estos extraños materiales ajenos pasan absorbidos al estilo individual de Borges $\mathrm{y}$ no son de ninguna manera gratuitos. Se justifican plenamente dentro de la estructura interior del cuento por su papel orientador. De este modo, el lector iniciado no deja de experimentar cierto placer estético al ver cumplida una premisa ya establecida. Es decir, participa del juego intelectual que está desarrollándose en la narración. Borges se atreve a confesar lo que no es suyo y también, mediante este recurso, logra acentuar la buscada atmósfera de rareza que caracteriza sus ficciones. Suele reprochársele la invención de libros y autores ilusorios, pero tal procedimiento, cuya frecuencia haya sido exagerada con toda probabilidad, no puede condenarse dentro de un género fantástico. No olvidemos tampoco que declara cómo ha preferido "la escritura de notas sobre libros imaginarios" (Prólogo a $E l$ jardín de senderos que se bifurcan). El segundo capítulo del libro insiste en la exactitud de su técnica narrativa. Cada com-

10 Refiriéndose a la erudición de Borges, Ibarra dice lo siguiente: "... Mais Borges ne semble poser jamais autrement quainsi son dessein: tirer le parti le plus vif et personnel possible d'une petite poignée d'informations presque toujours sommaires, toujours capricieuses. Non certes qu'honneté soit chez lui un vain mot; mais c'est un mot dont il a sans doute, comme de tant d'autres, sophistiqué le sens" (lo subrayado es nuestro). Ibarra, Art. cit., p. 10. 
ponente del relato forma parte del todo y aun los detalles más minuciosos están en función de un fin unitario. No desentona el ejemplo clásico de Edipo Rey citado por los críticos, para recalcar la deliberada organización de las ficciones borgeanas. Pasan luego a estudiar la ambigüedad del autor (III), la cual corresponde, según ellos, a un deseo de presentar una realidad en toda su vasta complejidad. ${ }^{11}$ Otro plano de la misma tendencia especulativa se manifiesta en su preferencia por heresiarcas y doctrinas sospechosas. Gusta, pues, de la doble pers. pectiva y sabe aprovechar, por ejemplo, todas las posibilidades del tema de la traición para señalar la duplicidad humana. El capítulo siguiente (IV) arranca de una pregunta: ¿qué es narrar una vida para Borges y cómo soluciona el problema? Su nada convencional concepto de la biografía se complica por es. tar relacionado con otras teorías predilectas de su obra (la concatenación infinita de sucesos y hechos, el destino, el tiempo cíclico, la identidad). Como Plutarco - otra vez un antecedente clásico citado por los autores- Borges no escribe historias sino vidas. Una biografía, según él, debe captar lo esencial y lo único de la existencia. Es, pues, una tarea discriminadora que tiene por objeto reducir lo múltiple a lo singular. Dejando de lado su Evaristo Carriego (1930), nos permitimos otros ejemplos. En el relato de la "Biografía de Tadeo Isidoro Cruz" (El Aleph) Borges no cuenta su historia. Se limita más bien a una sola noche, puesto que la sustancia de una vida está circuns. crita a un momento esencial cuando el hombre llega a saber quién es. En la "Historia del guerrero y la cautiva", del mismo libro, los dos protagonistas, alejados en el espacio y el tiempo, están identificados en uno solo por haber compartido una circunstancia similar. En ambos casos se ve cómo Borges suele articular sus biografías con una teoría del destino y con la idea de que la vida de un hombre es la vida de todos los hombres.

11 Dicen Tamayo y Ruiz-Díaz textualmente: ". . Inútil sería suponer, insistimos, que todo se reduce a un procedimiento que busca el desconcierto de los lec. tores. La fácil imprecisión de situaciones y personajes ambiguos responde, verdaderamente, a una intensa preocupación de ofrecernos realidades en su complejidad; darle sentido equívoco a una realidad es hacerla más transparente, es aceptar su carácter mismo de inconclusa e interina que los rígidos esquemas habituales suplan. tan con una simplicidad engañosa, falaz" (p. 50). 
Al ocuparse de este aspecto constante de su obra (V), Tamayo y Ruiz-Díaz apuntan que la inteligibilidad de una vida, para Borges, resulta precisamente del descubrimiento del destino propio.

Un rasgo distintivo de nuestra época actual es, sin duda, su obsesionante preocupación temporal. Y, de hecho, el tema del tiempo es básico en Borges y forma parte integral de sus especulaciones metafísicas (negación del tiempo, eterno retor. no). Al referirse a ese tópico (VI), puntualizan Tamayo y RuizDíaz cómo en Borges el futuro está prefigurado y limitado por el pasado. ${ }^{12}$ Después de haber comentado la temporalidad de los relatos de Borges, pasan al papel de la memoria y el olvido. Otras páginas estudian el tempo de su estilo, o sean los recursos expresivos de Borges para transmitir una profunda impresión temporal dentro de la narración misma. Insistiendo acer. tadamente en la infatigable disciplina artística que le hace pesar cuidadosamente todo elemento expresivo, los críticos luego plantean el problema de la realidad en su obra (VII). Un mundo fantástico, irreal y así ilimitado en sus posibilidades. $\mathrm{Y}$ uno de los valores más fecundos en Borges es, precisamente, haber abierto nuevos mundos para la creación. Sin embargo, conviene notar que dentro de su universo fantástico imperan las rigurosas leyes de la inteligencia y la lógica (Borges, de paso, ha censurado la incoherencia del género psicológico). De esta manera, arranca de lo irreal para iluminar nuevas y oscuras zonas de la realidad misma. La quiere descifrar y aclarar. Reiteradamente ha afirmado Borges la inutilidad de las doctrinas filosóficas que han intentado explicar los misterios últimos del mundo. Toma,

12 Otra vez los citamos: ". . Con riqueza de procedimientos técnicos que toca en ocasiones al virtuosismo, Borges cancela la eventualidad futura en favor de la postulación de lo que irrevocablemente fue y por haber sido así, obligatoriamente será. El tiempo de estos relatos carece de mañana. Si queremos mantener el escueto trimembre (pasado-presente-futuro), digamos que cada personaje, cada desarrollo de la trama tiene en el límite de su presente un espejo. La superficie pulida tefleja el ayer y de ahí resulta que el ingreso en este prefijado futuro es más bien un regreso; un internarse en un pasado que en lo esencial consiste en su repetición enmascarada de porvenir. De tal manera, en lugar de una variabilidad del tiempo, encontramos una obligatoria sumisión a un orden ineluctable que aunque revista formas de temporalidad y cambio, consiste, y aquí llamamos otra vez la atención, en identidad inevitable, en inconmovible reposo" (p. 112). 
pues, una premisa fantástica y, mediante una plenitud de recursos, la lleva a sus últimas consecuencias. ${ }^{13}$ Uno de los capítulos de mayores posibilidades en ese libro, cuyas excelencias han extendido nuestro comentario, es el último en que se resumen, en forma quizá demasiado sintética, algunos rasgos esenciales de la estética y el arte de Borges. Tamayo y Ruiz-Díaz revisan sus profundas y constantes preocupaciones linguíisticas ${ }^{14}$ (el restablecimiento léxico, la precisión y corrección, las afectaciones idiomáticas - hispanismo y criollismo- que rechaza Borges); $\epsilon$ l concepto funcional del estilo y la economía verbal que dan por resultado la perfecta adecuación extensiva de sus relatos; ${ }^{15}$ la metáfora; ${ }^{16}$ y la patria cuya esencialidad oculta exige mucho más que lo puramente exterior y visible concretado en un estrecho localismo verbal y temático. ${ }^{17}$

13 E. Anderson Imbert ["Desagravio a Borges", ya citado] dice: "... Nadie tomará en serio sus opiniones; pero su maliciosa dialéctica fertiliza sus creaciones, a las que nadie dejará de tomar en serio" (p. 24) y, años más tarde, esta observación pasará a su Historia de la literatura bispanoamericana, México: Fondo de Cultura Económica, 1954, p. 324.

14 Sobre la lengua de Borges, es sumamente útil el trabajo de Ana María Barrenechea, "Borges y el lenguaje", NRFH, VII (Núms. 3-4, 1953), pp. 551-569.

La misma autora acaba de publicar otro extenso e importante trabajo sobre Borges: "El infinito en la obra de Borges", NRFH, X (Núm. 1, enero-marzo de 1956), pp. 13-35.

15 Las mejores aproximaciones que tenemos sobre el estilo de Borges son, desde lnego, los conocidos trabajos de Amado Alonso: "Borges, narrador", Sur, V (Núm. 14, nov. de 1935), pp. 105-115 y su nota aparecida en el citado "Desagravio a Borges", pp. 15-17.

16 Hay muchísimos textos borgeanos que se ocupan precisamente de la metáfora y con frecuencia están relacionados con el ultraísmo que va repudiando. Es interesante comparar lo que dijo el Borges ultraísta ["Ultraísmo", Nosotros, XV (Núm. 151, diciembre de 1921), pp. 466-471] con sus afirmaciones posteriores en El idioma de los argentinos (1928) y más tarde en Otras inquisiciones (1952). Sin embargo, recordemos las frases finales de "Noticias sobre los Kenningar" [Sur, II (Núm. 6, otoño de 1932), pp. 202-208]: "El ultraísta muerto cuyo fantasma sigue siempre habitándome, goza con estos juegos. Los dedico a una clara compañera de los heroicos días. A Norah Lange, cuya sangre los reconocerá por ventrזa" (p. 208).

17 Emir Rodríguez Monegal en su trabajo "El juicio de los parricidas: Borges entre Escila y Caribdis", ya citado, se ocupa brevemente del libro de Tamayo y Ruiz-Díaz. Cree con razón que es muy superior al libro de Ríos Patrón, pero sigue diciendo: ". . todo su esfuerzo carece de centro. Los jóvenes críticos no consiguen dar una visión unitaria de la creación de Borges. Muestran bien algunos temas, 
En su forma y método el libro de Ríos Patrón (Jorge Luis Borges) difiere notablemente del estudio antes comentado. No obstante, ambos trabajos, inspirados en una máxima voluntad de entendimiento, se completan, ofreciéndonos abundantes precisiones sobre la creación de Borges e interpretaciones de los textos. No se estorban, pues, y cada uno constituye una contribución al tema. En primer lugar, Ríos Patrón prefiere una visión panorámica y estudia, por lo tanto, los varios géneros cultivados por Borges, dedicando un capítulo al poeta (IV, pp. 6167 ), otro necesariamente más extenso al cuentista (V, pp. 79. 127) $\mathrm{y}$, después de un par de páginas referidas a los libros escritos en colaboración con Bioy Casares (VI, pp. 129-131), se ocupa finalmente del crítico y ensayista (VII, pp. 133-167). En estos apartados, Ríos Patrón ha enfocado en orden cronológico -libro por libro- la producción literaria de Borges. Haber logrado cierta amplitud gracias a este método no quiere decir que haya descuidado el análisis mismo de la obra. Los capítulos anteriores (I-III, pp. 9-60), de índole más general, estudian respectivamente el itinerario personal, el pensamiento (mundo y cultura, realidad, temas y motivos) y el estilo de Borges.

Por haberse empeñado más en la exégesis textual Tamayo y Ruiz-Díaz, falta casi por completo en su trabajo la historia literaria. En cambio, Ríos Patrón, de acuerdo a su claro propósito de divulgación, se cuida mucho de ubicar a Borges dentro de su clima intelectual (pp. 9-19, 61-63). Los mínimos datos incorporados a su trabajo sobre la literatura argentina contemporá.

analizan bien algunos cuentos, intentan (con regular fortuna) forjar una clave. Pero el centro de esa creación literaria y humana se les escapa..." (p. 23). En otra parte, Emir Rodríguez Monegal nos ofrece su propia solución cuando dice con respecto a la unidad central de la obra de Borges: "... Aquí no se esboza una explicación única. Sólo se pretende confirmar, con algún detalle estilístico, una intuición invasora: la de una visible identidad entre el mundo de las ficciones y el mundo que habita realmente su inventor; la intuición de que la realidad es para Borges pesadillesca, de que sus ficciones (fantásticas o realistas) son verdaderas en el sentido de que copian una realidad alucinada: la de su autor... La trama de las intuiciones de Borges y la trama de sus ficciones son una y la misma cosa. Debajo de las metáforas narrativas (que suelen llamarse cuentos) se esconde una concepción idealista de la Realidad, una metafísica hondamente entaizada en las experiencias del hombre. Por eso, este hombre Borges (este creador) es también John Vincent Moon el traidor, es también Eric Lönrot el detective, es también Irineo Funes el memorioso". "Borges: Teoría y práctica", pp. 156-157. 
nea (revistas, polémicas, autores) no interesan, desde luego, tanto al especialista en la materia como a los que no están bien informados sobre las promociones literarias de los últimos treinta años en el Río de la Plata. Dentro de su método, en parte histórico, conviene notar que Ríos Patrón maneja con acierto sus materiales bibliográficos, citando textos ajenos que son a veces de consulta muy difícil. Otro mérito positivo: se incluye al final una bibliografía sumamente útil, no siempre rigurosa, pero ciertamente la más completa que tenemos hasta ahora sobre Borges (pp. 171-179).

Los detractores de Borges, como ya hemos señalado, pre-. tenden reprocharle una frialdad y una deshumanización por la extremada intelectualización de su obra. Ríos Patrón, uno de sus más entusiastas defensores, se apresura a desterrar tal impugnación y, a lo largo de su ensayo (p. ej., pp. 17-18, 24-26, 28-30, 45-47, 119-120), insiste más bien en las profundas raíces humanas que caracterizan sus escritos. ${ }^{18}$ Con respecto a la patria - otra piedra de toque para la crítica adversa- recalcar sus defectos, lo cual ha hecho Borges en más de una ocasión, no implica una indiferencia por lo argentino, sino una excepcional madurez de espíritu (pp. 26-28).

Una posible clave, no explotada lo bastante por la crítica anterior según Ríos Patrón, para comprender plenamente su fondo temático y concisión estilística se encuentra en las filosofías orientales, cuyas relaciones sobre todo con el tiempo y la muerte aprovecha en el segundo capítulo al enfocar el pensamiento de Borges (II). Son interesantes las páginas que dedica al motivo obsesionante del laberinto (pp. 39-45), publicadas antes en la revista Sur [Núm. 233, marzo y abril de 1955, pp. 75-79]. Cuando examina el estilo conciso de Borges (III), que es en él un modo de pensar, acertadamente pone de relieve sus procedimientos expresionistas y el fecundo contacto con Quevedo (de quien Borges se ha ocupado en sus notas críticas varias veces). Ambos escritores se agrupan en una misma familia por su curiosidad lingüística y dominio completo del instrumento expresi-

18 Los que sólo ven su inhumanidad "... sólo consiguen - dice Ríos Patrónratificar su personal imposibilidad de comprenderlo. Tal valdría negar un teorema por no entender matemáticas" (p. 46). 
vo. Sin embargo, al notar esos parecidos, observamos que Ríos Patrón no alude a Unamuno. Y, de paso, nos preguntamos si no hubiera convenido una mínima referencia al Lugones prosista tan fuertemente entroncado también con Quevedo. Para es. tudiar al expresionismo de Borges parte de unas definiciones (Alfredo la Guardia, Guillermo de Torre, Amado Alonso); ajusta sus observaciones a los conocidos esquemas de Elise Richter; y luego completa el capítulo una larga cita de Amado Alonso. Quizá no sea justo criticarle ese método, pero, a nuestro modo de ver, Ríos Patrón hubiera podido encontrar soluciones más personales para iluminar ese aspecto vital de Borges. Sin dejar de tener en cuenta, como base obligatoria, los magníficos estudios parciales de Amado Alonso sobre Borges y la seria contribución de Ana María Barrenechea, todavía queda por hacer un análisis estilístico de tan rica prosa. Este no es, claro está, un reparo que le hacemos a Ríos Patrón. Nada más lejos' de su intención que abordar un tema tan complejo y amplio dentro de los límites estrictos de su presente libro.

Aunque Borges inicia su labor de poeta afiliado al ultraísmo, aun desde el primer momento se aleja consciente y progresivamente de toda escuela literaria. Sus versos han sido objeto de las críticas más dispares, las cuales no nos proponemos resu. mir aquí, pero, en la opinión de Ríos Patrón, logra fundir en ellos una auténtica visión nativa que es, al mismo tiempo, universal (IV). Una poesía, pues, que no sólo obedece al estímulo emocional sino también a la continua búsqueda metafísica. Aje. na al retoricismo vacuo, a la musicalidad exterior y al sentimentalismo erótico, es más bien, como toda su obra, producto de una aguda sensibilidad vigilada constantemente por la inteligencia. Aunque no los cita Ríos Patrón, nos permitimos transcribir los famosos versos de Borges:

Yo solicito de mi verso que no me contradiga, y es mucho. Que no sea persistencia de hermosura, pero si de certeza

[espiritual.

Más amplio y más original es la sección que trata el arte de contar en Borges (V). Arrancando de su primer libro de cuentos (Historia universal de la infamia, 1935), pasa por las etapas subsiguientes, para desembocar en un análisis detenido (pp. 120. 
124) de "El Sur" (1953), narración de las más típicas pero no recogida en libro, y unas breves observaciones sobre "El fin" y "La hermana de Eloísa", esta última escrita en colaboración. ${ }^{19}$ Ante la imposibilidad de referirse con la debida extensión a to. dos los relatos, selecciona para comentario más dilatado los que considera definitorios ("El jardín de senderos que se bifurcan", 91-94; "Tlön, Uqbar, Orbis Tertius", 94-101; "El inmortal", 115-120), lo cual no le hace suprimir aproximaciones sintéticas a otros muchos. Pero inexplicablemente no sólo Ríos Patrón sino también Tamayo y Ruiz-Díaz apenas aluden a "Funes el memorioso". Rastrea el crítico los temas y motivos capitales (la identidad e identificación, el tiempo, el sentimiento del caos, el laberinto, la heterodoxia, las simetrías y los paralelismos, el sueno) a los cuales repetidamente vuelve Borges con marcada insistencia pero siempre desde nuevas y revitalizadoras perspectivas.

Borges es fundamentalmente un escritor fantástico, de ficciones tan brillantes como enigmáticas, pero no son menos extensas sus actividades de crítico y comentador de literaturas. Dueño de una cultura universal pocas veces igualada, siempre nos asombran sus vastos conocimientos de obras y autores extranjeros. La crítica y la ficción suelen cruzarse para confirmar una vez más la unicidad y singularidad de Borges escritor. Dos caras, pues, de una misma moneda. Conviene señalar con qué frecuencia sus notas de crítica, atacadas con tanta acrimonia, se ocupan precisamente del arte de escribir. El último capítulo del libro de Ríos Patrón tiene por objeto completar la trayectoria del autor, procurando establecer en tan abundantes materiales las líneas esenciales de esta fecunda labor de ensayista, una labor sostenida sin tregua durante toda su vida literaria. (VII). A manera de resumen, no hay por qué vacilar en afirmar que el trabajo de Ríos Patrón cumple con su enunciado propósito: contribuir al estudio de la literatura argentina a través de la obra de una de sus mayores figuras. $\mathrm{Y}$ frente a Borges, una admiración ilimitada.

119 Ese relato da título a un volumen de 1955 que contiene dos cuentos de Borges ("La escritura de Dios" de El Alepb y "El fin" ya mencionado), dos de Mercedes Levinson y el que escribieron en colaboración. 
De menos extensión y de factura sumamente diferente es el ensayo de Adolfo Prieto (Borges y la nueva generación). Conforme al título, un valor lateral, si no el más importante, de su estudio es enjuiciar los ideales y aspiraciones de su propia generación..$^{20}$ La actitud de Prieto ante la obra de Borges es severa. Reproches y juicios duros. Es difícil aceptar sus opiniones - de hecho, algunas son muy discutibles y constituyen serios reparos- pero aún así el lector no dejará de admirar la aparente honestidad y valentía con que expresa sus vehementes convicciones. Lo que no puede perdonársele, sin embargo, es su ligereza crítica, su arbitrariedad y el grave error de juzgar a Borges según una filosofía del arte francamente ajena a la obra que estudia. En obras de esta índole suele haber un tono agresivo que molesta. Aquí no. La sinceridad y la falta de invectiva se combinan para eliminar tales lacras. Prieto no estudia a Borges con espíritu combativo y totalmente negativo. Sencillamente está desvinculado de este tipo de literatura. Respeta la inteligencia, la imaginación y la sutileza de Borges; no puede imaginarse una literatura argentina sin él; pero, al mismo tiempo, se atreve a afirmar la esterilidad de sus escritos. Tan singulares que nacen y indefectiblemente mueren en Borges. Según Prieto, los jóvenes de su generación se sienten ajenos y extraños a una literatura concebida como un lujo y alejada de la circunstancia actual. Por otra parte, cita los casos de Martínez Estrada, Marechal y Mallea, quienes, sin sacrificar su arte, han logrado mejores soluciones integrándose más a su medio que Borges.

Adolfo Prieto parte de dos desajustes que existen hoy para el lector de Borges. La intención de su trabajo es indagar sus causas. La primera y más importante desproporción es la que hay entre el valor intrínseco de la obra y el prestigio que goza ("Un gran literato sin literatura", p. 84). También Lugones en su época, según nos dice Prieto, ocupaba una situación análo. ga: un fenómeno de presencia más que autor de una obra va-

20 Para una excelente caracterización de las letras argentinas contemporáneas -sus ideales, sus sueños- remitimos al trabajo de Romualdo Brughetti ["Una nueva generación literaria argentina (1940-1950)". Cuadernos Americanos, LXIII (Núm. 3, mayo-junio 1952), pp. 261-281], quien insiste en la seriedad de su generación (pp. 261-266) y ofrece también unas agudas observaciones sintéticas sobre Borges y su papel en las últimas promociones literarias (pp. 267 y 269). 
liosa (i!)..$^{21}$ Más adelante apunta un desajuste secundario entre el esfuerzo y el resultado de la página escrita. Por lo demás, ve un abismo entre las extraordinarias dotes del escritor y el mérito de su producción literaria. Adolece, pues, de un defectc supremo: la carencia de valores humanos. Como las novelas de caballería y las pastoriles del XVI, géneros gratuitos, de vacío vital que se olvidan del hombre, meras curiosidades literarias y documentos de sociologia, morirá fatalmente el género policial y fantástico cultivado por Borges (i!). Hemos parafraseado fielmente las palabras de Prieto. No las comentamos por razones obvias.

Prieto se propone examinar el ensayo (pp. 29-46), la poesía (pp. 46-66) y el cuento (pp. 66-79) de Borges. Sinteticemos sus opiniones. La crítica, de naturaleza impresionista, se redu. ce a una serie de notas marginales o comentarios de un lector hedonista. Es inútil, innecesaria y prescindible..$^{22}$ La poesía a su vez se caracteriza por sus esquemas mentales y lógicos, su falta de lenguaje adecuado y el fracaso de la metáfora. Balance to. tal del verso: importante en la historia de la lírica argentina por representar una reacción contra la retórica modernista y por unos pocos hallazgos felices ("pensador a mitad de camino de poeta", p. 66). Nos permitimos un paréntesis ahora para transcribir la cita de Stevenson que encabeza la última edición de sus Poemas (1955): "I do not set up to be a poet. Only an all. around literary man: a man who talks, not one who sings... Excuse this apology; but I don't like to come before people who have a note of song, and let it be supposed I do not know the difference".

Prieto es menos duro con el Borges cuentista, sin embargo. Si bien sus narraciones se agotan como mero pasatiempo,

21 Borges, por su parte, ha enitido muchos juicios sobre Lugones. Burlas ("Nulario sentimental", por ejemplo) y elogios. Recordemos otra página en el homenaje a Lugones, Nosotros, VII (Núms. 26-28, mayo-junio de 1938), pp. 150152. Además, el último libro de Borges es un ensayo sobre el poeta, pero desgraciadamente no conocemos todavía ese texto.

22 Aunque considera "irrespetuoso, injusto e insustancial" (p. 39) el artículo de Borges sobre el libro de Amético Castro La peculiaridad lingü̈stica rioplatense y su sentido bistórico (1941) y se detiene a comentarlo con cierta prolijidad (pp. 39-46), por lo general Adolfo Prieto pasa por alto sus escritos sobre problemas lingüísticos. 
admite sus méritos de excelente prosista y su virtuosismo personal. Autor, pues, de media docena de relatos, entre los cuales incluye con acierto, al lado de otros más divulgados ("El inmortal", "Hombre de la esquina rosada", "Funes el memorioso"), "La casa de Asterión". Estamos de vuelta otra vez en el declarado punto de partida: el desajuste entre la calidad de la obra de Borges y su importancia en las letras contemporáneas. Unas conclusiones (pp. 81-90) resumen sus juicios e insisten en la actitud generacional frente a Borges. Tildado del estigma de bizantinismo, condena su arte por una posición lúdica ante la vida, rasgo propio de los escritores martinfierristas, frente a la seriedad de hoy ("El dorado presente de ellos es el opaco pre. sente nuestro', p. 88)..$^{23}$

Nos referimos antes a ciertos reparos serios que pueden hacerse al ensayo de Prieto. Señalarlos es tarea ingrata y displicente, pero algunos no deben callarse. Aunque el lector no comparta del todo las doctrinas estéticas de Prieto, cuyo parecido con Sartre y la literatura comprometida es bien claro, las tiene que respetar por motivos de objetividad dentro de la intención ideológica del trabajo. No hay por qué refutarlas o, mejor dicho, matizarlas. Ni tampoco sería procedente discutir los valores humanos y argentinos de la obra de Borges. Basta remitir a la crítica más responsable. Sin embargo, quisiéramos aludir brevemente a ciertas posiciones teóricas muy aventuradas y frecuentemente insostenibles. Su definición del cuento, por ejemplo, desconcierta: "el hermano menor de la novela; si se quiere, el bosquejo de una posible novela. En última instancia, un me-

23 Hemos querido transcribir con más extensión unas palabras de Prieto: “...Este escritor, Borges, se entretiene (o se agota) en sus juegos del espíritu, mientras lo observa un grupo de iniciados. El grupo, obvio es declararlo, está compuesto de escritores (sólo un hombre de letras puede apreciar las sutilezas del oficio), pero de escritores con una connotación: la de contemporaneidad. Dicho en otras palabras o puntualizando las limitaciones, Borges es un escritor para los escritores de su generación. Creo que para nosotros, que respiramos otro clima, ya no lo es. Nos importa, como experiencia humana, reconocer y admirar el talento de un literato pero nos apura con mayor urgencia una literatura que trascienda el mero virtuosismo personal. Borges, empeñado en trabajat como joyas, ficciones al fin y al cabo minúsculas, desorienta como el artífice suizo que gasta media vida en repujar la apariencia de un mecanismo destinado a dar la hora como todos los hermanos de especie" (pp. 78-79). 
ro ejercicio retórico... pertenece a una especie secundaria del género novelesco (p. 60)". Por el momento tan sólo deseamos volver a insistir en cómo Borges conoce perfectamente bien su propia medida y las necesidades expresivas de su arte. ${ }^{24}$ Por lo demás, en el prólogo de $E l$ jardín de senderos que se bifurcan queda esbozada una posible contestación a su crítico: "Desvarío laborioso y empobrecedor el de componer vastos libros; el de explayar en quinientas páginas una idea cuya perfecta exposición oral cabe en pocos minutos". Aunque dicho así de paso, Borges siempre se ha sabido anticipar a las criticas que le ha. cen sus enemigos.

Adolfo Prieto también tiene una teoría de la crítica literaria. Dice lo siguiente en la página 34 de su libro: “...El verdadero crítico se coloca ante la obra literaria como ante algo total: no importa que luego deduzca de ella aspectos parciales: el punto de partida es la totalidad, y esa totalidad de la obra está presente a lo largo y a lo ancho de su labor de sondeo; lo que de ésta resulte en particular adquiere sentido remitiéndose a la imagen de aquélla". El lector que conoce a Borges echa de menos precisamente en Prieto el conocimiento total de la obra que se propone estudiar. Así parece, por lo menos, teniendo presente los textos que aduce Prieto para probar la inutilidad de Borges. El joven crítico afirma más adelante con razón que no es justo juzgar la poesía según el credo ultraísta (p. 46), pero, al estudiar sus metáforas (pp. 59-63), nos preguntamos si no cae precisamente en la trampa que ha deseado evitar. De paso, agregamos nosotros, siempre interesan más los motivos por los cuales un autor sale del ultraísmo que su inicial adhesión a esta escuela efímera. Observamos también que en ocasiones (metáfora, crítica) Prieto hubiera podido matizar y completar sus juicios mediante la transcripción de otros textos borgeanos. De hecho, en lo que respecta a la metáfora, podría escribirse todo un artículo sobre su teoria y evolución en Borges mismo. Por último discrepamos cuando opina Adolfo Prieto que durante treinta años de dedicarse a la literatura Borges no se toma la molestia de preguntarse qué es escribix (p. 84). Por lo contrario, el autoanálisis nos parece ser una de sus actividades más

24 'Tamayo y Ruiz-Díaz, op. cit., pp. 151-153. 
conscientes. Borges como ciertos protagonistas de los relatos ha logrado encontrar su propio destino de escritor. ${ }^{25}$

Al terminar esta reseña sobre Borges y la crítica más reciente, conviene mencionar que la revista Ciudad de Buenos Aires [Segundo y Tercer Trimestres, Núms. 2-3, 1955, pp. 1162] ha reunido en su sección "Los escritores argentinos" seis trabajos en torno a Borges, inclusive la bibliografía ordenada por Ríos Patrón con adiciones ahora de Horacio Jorge Becco. De estos artículos, el más interesante y comprensivo es el de César Fernández Moreno titulado "Esquema de Borges" (pp. 11. 31). Los demás, de menos extensión, prefieren estudiar aspectos parciales de su obra. Notamos que Adolfo Prieto es Secretario de Redacción de Ciudad pero los' críticos que se refieren a su ensayo lo hacen con elogios velados al mismo tiempo que lo refutan disimuladamente. Además, en el mismo número se incluye una agresiva "Nota de Roy Bartholomew" (pp. 93-101) que ataca el libro de Prieto y luego la respuesta de éste (pp. 101-106)..$^{26}$

Nuestra glosa bibliográfica, pues, ha pretendido resumir en parte la siempre apasionada crítica sobre Borges y señalar lateralmente unos aspectos generales de la obra de tan excelente literato. Muy exigente consigo mismo y con el lector, hay pocos escritores más conscientes de su propio oficio que Jorge Luis Borges.

\author{
Allen W. Phillips \\ Universidad de Chicago.
}

25 Si bien la influencia de Borges ha sido enorme sia duda, es verdad-y conviene advertirlo- que no se ha convertido en mentor espiritual de las nuevas generaciones argentinas por muchos motivos. Sobre ese aspecto de su personalidad y juicios en parte adversos es interesante el artículo de Emilio Sosa López, "Tendencias de la poesía argentina actual", Realidad, V (Núm. 13, enero-febrero 1949), p. 78.

26 Varias veces hemos citado el reciente artículo de Emir Rodríguez Monegal ("Borges: teoría y práctica") y no vacilamos en afirmar que es uno de los trabajos más serios, meditados y completos que hay sobre el escritor. Por su objetividad y penetración esas treinta páginas y pico merecen colocarse al lado de las mejores ale se han escrito sohre Roroes. 
